\title{
DISRUPTING THE BOUNDARIES OF THE ACADEME: CO-CREATING KNOWLEDGE AND SEX WORK 'ACADEMIC-ACTIVISM'
}

\section{LAURA CONNELLY \& TEELA SANDERS}

[Chapter Author 1: Dr Laura Connelly, University of Salford]

[Chapter Author 1: L.J.Connelly@salford.ac.uk]

[Chapter Author 2: Professor Teela Sanders]

[Chapter Author 2: Teela.Sanders@leicester.ac.uk]

\section{AUTHOR BIOGRAPHIES}

Laura Connelly is a Lecturer in Criminology at the University of Salford. Her research interests include: the sex industry, migration, 'modern slavery', and 'post-racial' theory. There is a social justice element to Laura's work, which centres on the rights of (migrant) sex workers and challenging police injustices.

Teela Sanders is Professor of Criminology at the University of Leicester. Her research focuses on the intersections between gender, regulation, governance and crime, specifically in relation to the sex industry. Teela is working on a two-year Leverhulme Research Fellowship titled 'Revisiting the Brothels'.

\section{ABSTRACT:}

In this chapter, we reflect on how the criminological agenda can move towards disrupting the boundaries that exist between the academe and sex work activism. We do so as academics who strive to affect social change outside of the academe but we do not attempt to offer a prescriptive 'how to guide'. Indeed, we are ourselves still grappling with the challenges of, and learning to be better at, 'academic-activism.' We begin by shining light on the activist underpinnings of the sex workers' rights movement, before we outline some of the key scholarship in sex work studies, drawing particular attention to that which seeks to bring about social change. We then explore the utility of participatory action research (PAR) to sex work studies and reflect on how a PAR-inspired approach was used in the Beyond the Gaze research project. Here, we cast a critically-reflexive eye over the unique realities, including the challenges, of integrating sex worker 'peer researchers' within the research team. We conclude by considering how the criminological agenda must adapt if we truly want to bring about positive social change for sex workers, as well as how the current system of Higher Education ultimately stymies 'academic-activist' approaches to research.

KEYWORDS: (Please supply up to 6 keywords for your Chapter)

1. Sex work

2. Participatory-Action Research

3. Academic-activism

4. Peer researchers

5. Social change

6. Decriminalisation 


\section{Main Body:}

Processes of globalisation have enabled the sex industry to grow, diversify, and establish itself as a visible part of the global economy (Brents and Sanders, 2010). At the same time, sex work scholarship has burgeoned. Some of this scholarship is applied in nature and complements the rich tradition of activism within the sex workers' rights movement. This applied scholarship often seeks to bolster calls, long since articulated by sex workers (Phetersen, 1989), for the decriminalisation of the sex industry and for recognition of the labour rights of those who sell sex. There is therefore no denying that sex work research is inherently political. It is not - and can never be - objective in nature. We, like all sex work academics, hold our own ideological positions around sex and sexuality, patriarchy, empowerment and all issues that are feminist. These ideological positions - crystallised by the polarised 'sex wars' (see: Ward and Wylie 2017; Weitzer 2007) - are deeply embedded within opinions and attitudes about the sex industry and those operating within it, whether sellers, buyers or facilitators. They inform the nature of our research, how we go about conducting our research, and the purpose of our research. In essence, our ideas about what selling sex for commercial gain actually is shape our epistemologies. Academics working within the sex workers' rights tradition are clear about the purpose of our work: it is in service to the sex workers' rights movement. The polarised debates around sex work are not, however, the preserve of academics, rather they inform real life tussles in politics, policy and everyday practice. Sex workers generally, and sex workers who are also activists particularly, grapple with the issues central to these debates (some would say life and death issues) on a daily basis.

In this chapter, we reflect on how the criminological agenda can move towards disrupting the boundaries that exist between the academe and activism. We begin by shining light on the activist underpinnings of the sex workers' rights movement, before we outline some of the key scholarship in sex work studies, drawing particular attention to that which seeks to bring about social change. The chapter then moves on to explore the utility of participatory action research (PAR) to sex work studies, before we reflect on how a PAR-inspired approach was used in the Beyond the Gaze research project. Here, we cast a critically-reflexive eye over the unique realities, including the challenges, of integrating sex worker 'peer researchers' within the research team. We conclude by considering how the criminological agenda must adapt if we want to bring about positive social change beyond the academe, as well as how the current system of Higher Education ultimately stymies 'academic-activist' approaches to research. Although we use the term 'academic-activism' throughout this chapter, we recognise its fuzzy nature. We use the term in a broad sense - to denote sex work scholarship that seeks to bring about positive social change for sex worker - and do not prescribe what is involved in sex work 'academic-activism.' Nor do we seek to offer a 'how to' guide. We ourselves are still learning what 'academic-activism' looks like, the challenges involved in it, and how to be better at it.

Before we move on, it is important we note that sex workers who have worked in various coresearcher roles, including on the Beyond the Gaze project foregrounded in this chapter, have shaped this chapter and the ideas explored within it. They have chosen not to be named authors on this chapter for further fear of 'outing' themselves, and jeopardising university degrees and future careers. This is testament to the very complex challenges researchers face when engaging participants as coproducers of knowledge when the subject is 'tricky' in some way: laden with stigma and negative 
consequences by association. We hope that in time, as PAR becomes embedded within social science even further, these methodological tools will be one way to eradicate the stigma sex workers experience.

\section{Sex worker activism: grassroots engagement with core issues}

Sex workers have a rich history of self-organising to mobilize against criminalisation and the discourses that simultaneously cast them as victim and 'Other'. Largely devoid of state protection, sex workers have also had to develop their own collective ways of managing risk and responding to harm (Sanders et al., 2018). In the UK, the sex workers' rights movement is led by grassroots organisations working regionally, nationally, and internationally to demand human rights that enable safe and dignified working. 'Yet, sex work continues not to be recognised as a legitimate form of labour in the UK, with a continued struggle to even recognise the differences between forced and voluntary prostitution in policy discourses. Both here and globally, the sex workers' rights movement is therefore forced to fight on many fronts, against state repression; carceral and anti-prostitution feminism; the rescue industry; as well as the heteronormative, imperialist, capitalist, white supremist, patriarchal forces that structure the lived experiences of sex workers. Whilst some sex worker activists advocate for the mainstreaming of sex work into the labour market, others agitate against the broader socio-economic processes that induce precarity (Hardy and Cruz, 2018). In this regard, we have seen sex work activism overlap with activisms that challenge border control, immigration detention, and those that make demands for prison abolition, LGBTQ+ rights, gender equality, and the end to austerity (SWARM, 2019).

There are any number of examples of sex worker-led activism in the UK and globally. One of the oldest sex worker activist groups in the UK, the English Collective of Prostitutes (ECP), began its life in the early 1980s, and grew out of organising around women's experiences of poverty. It claimed the first successful prosecution of the rape of a sex worker in 1995 and is currently leading a national decriminalisation campaign. ECP also co-ordinated a symposium in 2015, hosted by John McDonald MP, which 'brought together for the first time in the UK the largest and most robust body of evidence to date on decriminalisation' (English Collective of Prostitutes, 2016: 4). Whilst it did not bring about immediate policy change, the significance of this event - which was attended by cross-party MPs in the prestigious House of Commons - should not be underestimated. The ECP's frequent interventions are much needed in the context of ubiquitous pressure from abolitionists generally, and in renewed calls from the All-Party Parliamentary Group for Prostitution for the government to criminalise the purchase of sex particularly. Further afield, three Ontario-based sex workers won a landmark legal case in Canada in 2013 which saw provisions under the criminal code ruled to violate sex workers' rights to security and freedom of expression (Canadian Alliance for Sex Work Law Reform, 2014). On the African continent, brothel-based sex workers in Nigeria have formed the Women of Power Initiative and have engaged in protests against the violation of their labour rights. In Kenya, the Bar Hostess Empowerment and Support project is a rights-based organisation with over 20,000 sex workers connected to it, using peer educators to deliver services and work towards resisting injustices (Hassan, Sanders, Mwangi, 2018). The Durbar Mahila Samanwaya Committee (2017) in India comprising 65,000 self-organising female, male and transgender sex workers - works to identify and 
challenge the socio-structural factors that perpetuate the material disadvantages and social exclusion of sex workers.

As sex work academics, we must ensure our work complements the sex worker-led movement, and recognise that this may involve taking direction from sex workers and being assistants in the jointcause, not the leaders. While it is only right that sex worker activism is led by sex workers, there is no doubt a role that can be played by non-sex working activists and organisations. Although we should challenge the marginalisation and silencing of sex worker voices, the reality of how these processes operate means that the sex workers' rights movement has the greatest chance of success if it is supported by allies. Indeed, sex workers' calls for decriminalisation have been bolstered in recent years by Amnesty International, UNAIDS and the World Health Organisation, whom have each declared support for the decriminalised model of sex industry regulation. Sex work academics can play, and have played, a significant role in supporting sex workers in their fight for workers' rights, safe working, and decriminalisation. With this in mind, we now explore the current state of sex work scholarship.

\section{Key contributions of sex work scholarship}

Sex work studies is a growing field of research characterised by diversity, both in its philosophical and methodological approaches, and in its substantive foci. Some scholarship has focused on the lived experiences on those selling sex across a range of sex markets: outdoors (O'Neill et al., 2008; Sanders, 2009); in brothels, saunas and parlours (Pitcher, 2015); and in the escorting sector, which itself has been radically transformed by the advent of the internet (Cunningham and Kendall, 2011; Jarvis-King, forthcoming; Sanders, Connelly and Jarvis-King, 2016; Sanders et al., 2018). Other scholars have focused on the customers of sex workers (Brooks-Gordon, 2010; Sanders, 2008; Brents, Sanders and Wakefield 2020); the governance of sex work and the impact of different regulatory systems (Abel, 2014; Jahnsen and Wagenaar, 2017; Levy and Jakobsson, 2014); migrant sex work and (its conflation with) sex trafficking (Agustín, 2007; Mai, 2013); and the phenomenon of sex tourism (Kempadoo, 2004; Rivers Moore, 2016; Sanchez Taylor, 2006). Some sex work scholarship has sought to challenge the hegemonic casting of sex workers as 'risky' - the perennial Other - to instead draw attention to the risks that they encounter. This body of research not only exposes sex workers' heightened risk of physical violence - from (a minority of) clients, vigilantes, police officers, controllers, and others (Campbell and Stoops, 2010; Kinnell, 2008) - but also, how sex workers are deterred from reporting victimisation. This may be due to the (perceived) risk of: arrest, the arrest of their co-workers and/or clients, the closure of the premises in which they work, and/or public identification (Boff, 2012; Connelly, Kamerade and Sanders, 2018; Klambauer, 2018). The sex work studies field is thus burgeoning with work that contests the marginalisation and stigmatisation of sex workers.

Whilst there are strong theoretical traditions within sex work studies, much of the scholarship is applied in nature - that is to say, it aims to improve the lived realities of sex workers. In this regard, many sex work scholars use their work to either implicitly contribute to, or explicitly lobby for, social change. Much of this applied scholarship has focused particularly on how the sex industry should be regulated and how best to protect sex workers. Researchers have, for example, sought to influence policy solutions by lobbing for changes to brothel legislation - which currently prevents sex workers from working in pairs/collectives - as well as for the wider decriminalisation of the sex industry. 
Scholars have been called upon to provide 'expert' testimony in the House of Commons and to local councils, most recently as part of the Leeds City Council's review of the Managed Approach: a multiagency initiate to address (outdoor) sex work in Leeds (Brown and Sanders, 2017). Others write media pieces, using the platform readily given to academics - though ironically denied to most sex workers - to disrupt the harmful narratives that proliferate around the sex industry. There is also a strong tradition within sex work studies of academics working in close partnership with sex worker support organisations and, perhaps to a lesser extent, sex worker collectives. These partnerships have no doubt become an increasing feature in recent years, with the current academic funding climate placing significant weight on partnership-approaches to research.

These examples of applied sex work research are, of course, not unlike copious other fields of research, which are often motived by the assumption that academic research can be put to work to alleviate the 'big problems of our society' (Piven, 2010: 806). Indeed, Gilbert (1997) suggests that the relationship between activism and academia is deeply rooted within the discipline of social policy. Advocacy activism has been the foundation of social policy's history and engagement with the academy, with major reports around poverty and exclusion in the 1800s, with child labour, work houses and slum deprivation being researched by 'academic activists'. Yet, the need for social change in the context of the sex industry has perhaps reached new levels of urgency in recent years. Migrant sex workers have, for example, reported an increased risk of arrest, detention and deportation since the EU-Referendum in June 2016 (English Collective of Prostitutes, 2019). The reported growth of the sex industry in the UK - including a $60 \%$ increase in outdoor sex work in Doncaster - has been widely attributed to austerity, with increasing numbers of women selling sex in order to provide for their children (English Collective of Prostitutes, 2016). With 160 known homicides between 1990 and 2016 alone (Sanders et al., 2017), perpetrators continue to murder sex workers, often with impunity. The police practice of 'brothel raids' continues, albeit under the guise of 'welfare visits' (SCOT-PEP, 2014), despite a wealth of evidence to document their harmful effects. All the while, the modern slavery agenda gains traction, operating to conflate trafficking for sexual exploitation and consensual sex work, and in turn, legitimise the control of women's bodies and state borders (Connelly, 2018). These factors combine to increase the precarity of sex workers' experiences, the effects of which are felt greatest by those already marginalised because of their citizenship status, race, sexuality and gender identity.

Of course, whilst academics adopting a sex workers' rights perspective have a strong tradition of applied research, it must be recognised that not all academics studying the sex industry use their research to advocate for decriminalisation. Some instead use their research to fight for the abolition of the sex industry. Often adopting a 'radical feminist' position, these scholars view the sex industry as inherently exploitative and consider commercial sex to represent the epitome of violence against women (Barry, 1995; Jeffreys, 2008). Weitzer (2010: 15) terms this position - one adopted by some influential organisations and campaign groups - the 'oppression paradigm' and suggest that it has led to a 'resurgent mythology of prostitution.' That is to say, claims are founded less upon evidence-based research and more upon an ideology informed by a universalistic victimhood perspective. Globally, this position has had notable success in terms of influencing policy and practice. Indeed, the purchase of sex was criminalised in Sweden in 1999, with Norway, France, Iceland, Ireland and Israel amongst the countries that have since followed suite. Kingston and Thomas (2018) note how this policy transfer 
has been conducted in a way that ignores the implications of banning the purchase of sex, leading to shoddy copy-catting of a policy without due attention and diligence to the context. In the UK, an enquiry by the All-Party Parliamentary Group for Prostitution (2018) called for the Government to introduce a law to criminalise the purchase of all sex. The enquiry report has, however, faced significant criticism from sex workers, sex worker support organisations, and academics of the sex worker's rights tradition. These criticisms have centred around the enquiry's exclusion of current sex workers, its conflation of trafficking and sex work, its penchant for hyperbole, and the role of a highprofile anti-prostitution advocate in the report's authorship (NUM, 2018; SWARM, 2017).

Although many of us working within the sex workers' rights tradition try to work outside of the choicecoercion binary - which is deemed by many to fail to capture the nuanced subjectivities of sex workers (Connelly, Jarvis-King and Ahearne, 2015; Mac and Smith, 2018) - we must remain mindful of the historical and contemporary influence of anti-prostitution academics. Not only has their influence manifested in relation to policy and practice but they have played no small part in driving a palpable wedge between sex workers and academics. As the sex working-feminist-activists Juno Mac and Molly Smith (2018) note, sex workers have been historically excluded, both physically and symbolically, from academia. The exclusion of sex workers from the physical spaces of conferences - something we as sex workers' rights academics are also complicit in - has been exacerbated by the dehumanising language employed by anti-prostitution academics and the false separation they draw between feminists and sex workers (Barry, 1979; Dworkin, 1987; MacKinnon, 1987 in Wahab, 2003). In this context, the distrust that sex workers have of academics is understandable. It is felt by some that non sex-working scholars have made careers 'on the backs' of sex workers, without sex workers accruing any benefit (Metzenrath, 1998: 11). If we, as sex workers' rights academics, are serious about bringing about positive social change for sex workers, we must work hard to gain their trust. The PAR tradition holds great potential in (re)building trusting, meaningful, sustainable relationships between academics and sex workers, and so we now move on to consider the use of PAR in sex work studies.

\section{Participatory action research and sex work studies}

Whilst a range of methodologies have been employed to understand the sex industry, traditional methods, such as the qualitative interview, have dominated sex work studies. Yet there is a growing swell of research that disrupts the traditional research agenda, including that which adopts a PAR approach. PAR is a social research methodology that involves the production and exchange of knowledge, and actions or interventions (O'Neill, 2001, 2007). At its core lies a desire for transformation, a concern both with the collective process of enquiry and the pursuit of social justice (Lewin, 1946; Borda, 1988 in O'Neill, 2010). PAR therefore does not conform to the positivist traditions of objectivity and neutrality since it recognises both that our own subjectivities inevitably influence the research process and that research is inevitably political in nature. For PAR researchers, research should have an agenda: one of creating positive social change. For Lewin (1946), whom is oft-regarded as one of the founders of the action research tradition, action research should involve democratic participation and should work to raise the self-esteem of marginalised social groups. In this respect, PAR focuses on the process as much as the outcomes of research and thus aims to foster an increased feeling of ownership amongst co-researchers and, where co-researchers are trained and supported, 
the development of additional skills (Clark et al., 2001). In this sense, PAR has both democratizing and emancipatory functions.

Voices and perspectives that are systematically marginalised by traditional approaches to research are instead central to the transformative potential of PAR. A key element of PAR involves the traditional 'subjects' of research becoming co-produces of knowledge (O'Neill, 2010), and in turn the subverting of traditional power-dynamics between the 'researcher' and 'subject.' In some forms of participatory research, the style of interview attempts to break down traditional hierarchies between the researcher and the 'researched', through developing a reciprocity whereby the researcher invests their personal identity in the research relationship and turns the interview into an interactive process (Jarvis-King, forthcoming; Letherby, 2003). In other forms, members of the community in question are trained as co-researchers and involved in the entire research process, including presentation of the findings and recommendations. In this sense, PAR does not privilege certain types of knowledge over others: scholarly knowledge is not considered of greater value than experiential knowledge. In keeping with a broader feminist philosophy, a high value is therefore placed on knowledge deriving from lived experience (Houh and Kalsem, 2015).

PAR is understood to be particularly beneficial when working with groups who are often faced with attempts to silence them. PAR has therefore become an increasingly popular methodology within sex industry research (Graça, Gonçalves and Martins, 2018; Oliveria, 2019; O'Neill, 2010; Wahab, 2003). The PAR approach seeks to shift the focus from research on sex workers to researching with sex workers. It recognises that sex workers are 'legitimate producers of knowledge about their own lives' (Oliveria, 2019: 87). It re-defines who the 'expert' is and what counts as expertise. Indeed, in this context, the 'expert by experience' has more knowledge to bring to the project than researchers outside or on the edge of the sex working community. In keeping with its transformative aims, researchers using PAR within sex work studies recognises that by working with the very people who have the greatest stake in the issue or problem being researched (sex workers), we have the best chance of developing purposeful knowledge leading to social change. Social change, for O'Neill (2010), is therefore only possible through meaningful and sustained dialogue, mutual respect, and recognition.

Of course, it would be foolish to assume that sex work scholars are always an entirely separate group to the communities they study. Indeed, there are growing numbers of current and ex-sex workers working within academia and many more who, because of the stigma surrounding sex work, are likely to keep their dual identities private. For example, having worked as a dancer before embarking on her research study, Rachela Colosi's (2012) 'dancing-ethnographer' status no doubt enabled her, through prolonged participant observation, to achieve a level of richness in her data that would be unachievable to 'outsiders'. Colosi's work reflects a longer tradition in the US where autoethnographic studies of some sex markets have been the bedrock of knowledge in their area; Frank (1998) and Egan's (2003) work is the perhaps the most obvious in that regard but Jones (2019) has more recently conducted work on webcamming. Whilst PAR has been used to good effect within sex work studies, in the next section we reflect on the realities, including the challenges, of using a PAR-informed approach in the Beyond the Gaze project, the largest study of internet-based sex work in the UK.

\section{Reflections on the use of PAR in the Beyond the Gaze project}


Beyond the Gaze $\mathrm{in}^{\mathrm{ii}}$ was a three-year project (2015-2018) that aimed to find out how digital technologies influence the sex industry, with core objectives to learn about safety, working conditions and regulation (see: Sanders et al., 2018). The project had three key beneficiary groups who were collaborators on the project: 1) sex workers who work online and within the broader sex work community; 2) projects and practitioners who work with sex workers - both statutory and third sector, including sexual health practitioners who deliver specific clinical services; 3 ) and the police (through the National Police Chiefs Council and the National Lead for Prostitution) and policymakers (local and national government). Data collection included a range of methods, which resulted in significant data sets, including: 641 sex worker survey responses; 1352 customer survey responses; 62 interviews with sex workers; 53 interviews with police officers from 16 forces; and interviews with 12 IT platforms. The principles of PAR were integral to the project and its engagement with the sex work and support project community. Core partners were a large sex work project (Basis Yorkshire), a national charity for third party reporting of crimes experienced by sex workers (National Ugly Mugs), and an online forum ran by escorts for escorts (Saafe). The infrastructure of the partnership model meant that collaboration was at the heart of the project, alongside the fundamental principle that experts from the sex work community should lead the research and its impact as much as possible and where resources would allow.

To ensure that we had insight from online sex workers (mainly independent escorts), it was important that sex workers who were using the internet for work were also integrated into the project. We had some resources - although never enough - to pay (sex worker) research assistants to engage with the design of the project, actualize the methodologies, create resources, and carry out various dissemination events. In many ways, the roles of the co-researchers were always a work in progress, a fine balance of what the resources would allow - including the several thousand pounds extra we successfully bid for to continue to include peers as much as possible after the original budget ran out - with the tight deadlines and complex administrative procedures of the university. Below we reflect on two core challenges the Beyond the Gaze project faced to using PAR in the sex work context.

\section{Institutional barriers to PAR}

When designing a project for a research council, with all the weight of expectation around fulfilling their detailed criterion and competing against the best social scientists in the country, one's framing of research around PAR may have the best of intentions. When one then tries to actualise the research design within the confines of the administrative systems of a university, the original PAR principles can often seem difficult to implement. This is largely because universities, with their cumbersome cogs of administrative machinery, are less set up to deal with anomalies in procedures or alternative research designs. When introducing paid researchers on an ad hoc basis - where there are sensitive issues around real names and addresses being divulged - how sex workers experience the interface of universities can be less than productive and efficient, and instead can seem inappropriate. Three key areas appeared particularly problematic in the organising of co-researchers within the Beyond the Gaze project. Firstly, having no formal contract or memorandum of understanding, ad hoc workers had a complex status as neither employees of the university nor self-employed workers. In hindsight, contracts which established the co-researchers as workers on the project could have helped ensure that they had rights as employees and that the 'casual' element of their employment status presented fewer issues, such as precarious working conditions. Secondly, the administrative payment system (largely because of tax rules and regulations) meant that there was little room for manoeuvre when paying co-researchers. Ensuring hours were claimed for and as little free labour happened as possible 
was hard to manage because the claim system was rigid. Several weeks would often pass by before individuals received remuneration for their work. The characteristics of ad hoc research work were therefore at odds with what sex workers were accustomed to through their own (sex) work in the informal cash economy. The third issue relating to the bureaucracy of the university emerged around accessing the university and its resources. Gaining email addresses and access to resources as a temporary casual worker can be prohibitive and whilst some effort is made by institutions to 'open up' the university to the wider community, there are hierarchies and engrained understandings of who a university is for that we are forced to contend with. This meant that most research meetings happened outside the university, utilising spaces which afforded anonymity and less scrutiny of individual statuses. Therefore, when administrative hurdles were pushing hard against new forms of engaging participants within a university setting, trying to stick closely to the principles of PAR was a constant battle. It was usually a case of 'square peg and round hole'. Our commitment to PAR meant that participatory elements informed all the activities as far as possible, within the complex circumstances presented to us.

\section{Stigma, outing, and recognition}

Whilst inclusivity can be designed into a project as far as possible, there are key issues in implementing PAR which can appear insurmountable and relate to the broader positioning of sex work (or any activity that is associated with 'deviant' behaviour) within society. Co-researchers in the Beyond the Gaze project were recruited because they were connected to the sex industry, which immediately presented the issue of outing. The project had clear processes for those who were already out as sex workers and those who were advisers 'in secret', in order to protect their anonymity. Yet involvement in a long-term project does not make the decisions around anonymity as clear cut as might first appear. Changes in circumstance, future careers, personal situations and/or simply a change in attitude about being known as a sex worker can make the issue of status a fluid and interchangeable reality (Bowen and Bungay 2015). There is also the issue of permanency to be considered if a coresearcher agrees to take part in a media piece or a film - as was the case in the Beyond the Gaze project - which then gathers a life of its own once released online and archived in websites. ${ }^{\text {iii }}$

These very real issues around anonymity and confidentiality bring with them dilemmas for academics who want the work and expertise of co-researchers recognised formally. Having co-researchers' names on conference proceedings, journal papers, books and other publications, or on engagement events which are in the public eye, is important for acknowledging their valued involvement and expertise. Yet for co-researchers in sex work research, this comes at a heavy cost since their sex work status is surmised, if not confirmed, and then rarely retractable. In the current socio-political climate, where the criminalisation and stigmatisation of sex work prevails in the UK (and many countries where sex work research is taking place), there are obvious concerns about sex work being officially recorded anywhere. Indeed, it is recognised that any association with sex work could be seriously detrimental to individuals, potentially resulting in arrest or, for migrant sex workers, deportation. The connections of sex work to deviance, criminality and quasi-illegal work/cultures will present similar social, political and institutional barriers for other academics wanting to engage sex workers as co-researchers.

Bowen and O'Doherty (2014) have provided community perspectives on participant-driven action research methods which have helped us evaluate the Beyond the Gaze project and think about the future approaches we might take. Some lessons going forward are therefore to think more about the co-development of research, design and tools, and the co-production of knowledge, outputs and outcomes. These should be much more central to the initial planning stages of the project, working 
out what is helpful for the sex work community and how 'sexperts' can be integrated in research collaborations from the outset. It is in light of these lessons that we now reflect on the broader potential for forging an 'academic-activist' approach to sex work research.

\section{Extending the criminological agenda: Forging an 'academic-activist' approach to sex work research}

Notwithstanding the definitional difficulties associated with the term 'academic-activism', much of the academic work within the sex workers' rights tradition seeks to bring about positive social change for sex workers. In this regard, we might understand it as 'academic-activist' in nature, albeit to varying extents and in vastly different ways, but in ways that try to be enabling to those with less power (Macioti and Garofalo Geymonat, 2016). Perhaps there has never been greater scope for 'academicactivism' than in the current Higher Education climate, with the Research Excellence Framework (REF) placing significant importance on generating 'impact' through research. Yet given that the REF operates to further the neoliberalisation of Higher Education rather than working in opposition to it, REF may foster a kind of 'impact' that does not seriously challenge the status quo. Whilst the current buzz words are often around 'inclusivity' as a framework for staff and students and 'research partnerships', we know from our own experience that the topic of sex work can throw these principles to the wind and can instead present concerns around reputational risk for universities that pre-empt bad media press. We are aware of colleagues who are working within sex work studies whose work has been silenced, despite doing pioneering, timely and important work which has policy relevance and a direct positive impact on sex workers and the broader sex industry community. Academics have been pressurised to not publish work, not speak to the media about their research findings, and not pursue dissemination events, conferences or other public engagement platforms where the university name could be connected with sex work. It is clear that institutions are worried about 'courtesy stigma' (Goffman, 1963): stigma by association. Institutions' concerns with reputational risk are certainly a factor academics must contend with when working in this area. Here, we suggest collaborative working across universities as one approach to mitigate such stigma as well as strong alliances and formalised partnerships with key NGOs. But we must also push back against the neoliberal university's attempts to silence our work and their commitment to upholding hegemonic power relations. We must challenge the hypocrisy that underpins their willingness to benefit financially via the REF from the 'impact' of our work, whilst trying to impose their own parameters upon what that impact should look like.

Whilst meaningful partnerships and co-creation are often core to 'academic-activist' work, the realities of the current system of Higher Education presents challenges to their operationalisation. Whilst funding is not a prerequisite to applied or activist-oriented research generally, or PAR specifically, it can be difficult to engage in 'ethical' research - that pays co-researchers for their labour - without it. The requirements that funding bodies impose upon researchers to have polished research questions and objectives for their funding proposals dictates that the research parameters are often (at least partially) defined before co-researchers are involved in a project. That is unless co-researchers are involved in the bid development process, which, given the competitive bidding process, can result in unpaid labour for no financial reward. This demonstrates that the current state of play within Higher Education is oppositional to some of the core principles of PAR. As such, the sex work 'academicactivist' must agitate for social change in the sex industry, whilst simultaneously agitating for changes within Higher Education.

Of course, the barriers facing sex work 'academic-activists' are not only constructed by our institutions. When grappling with an 'academic-activist' approach to research, one of the key issues 
that many academics working within sex work studies face is our 'outsider' status. That is to say, many of us are ourselves non-sex workers, a positionality that shapes this 'outsider' status. This brings certain (uncomfortable) benefits. Both of us, for example, have been afforded the opportunity to write about sex work in the mainstream and alternative medias. We are given a platform to speak about our research, which often involves sharing what sex workers have told us about their experiences. Ironically, the same opportunities are too frequently denied to sex workers. Furthermore, it is discomforting to us that whilst sex workers are so often punished by the state for their subversion (both in relation to their sex working and their activism), our privilege typically insulates us from the most negative of repercussions. Our 'academic activism' can, in some ways, benefit our career. Notwithstanding our privilege, our 'outsider' status can also raise particular challenges too. Such challenges can be from within the sex work (activist) community where there are sections that adopt the position that sex work research and activism should only be carried out by sex workers and that academics have no place or authority to do this. This response is understandable, particularly in a context in which abolitionists have frequently spoken on behalf of sex workers and accused sex workers of suffering from 'false consciousness.' Yet it is nonetheless a difficult issue to navigate. Perhaps one way we can disrupt these power dynamics is to insist that the platforms readily afforded to academics are shared with, or even offered up to, sex workers. We can refuse to engage with the media or participate in public events unless sex workers have been invited to contribute (Hardy, 2018, personal communication). It is only by relinquishing some of our own privilege that we can seek to bolster the rights of sex workers.

\section{Conclusion}

The sex worker rights' movement has a long history of sex worker-led activism that must be acknowledged and respected in any sex work scholarship. There is, however, an important place for academics within the sex workers' rights movement as allies and, as we contend in this chapter, our work should be in service to this movement. Yet notwithstanding the relative privilege of sex workers' rights academics, we are forced to fight on multiple fronts. Whilst our central aim must remain to use our work to bring about positive social change for sex workers by tackling the intersecting disadvantages they experience, we cannot escape the distractions that come from also fighting against the neoliberalisation of our workplaces and our anti-prostitution peers. Indeed, with tight funding landscapes presenting incredibly competitive funding terrains for researchers, marginalised groups such as sex workers are becoming increasingly side-lined as other social groups are nudged ahead on the priorities list. Although we have examined in this chapter the challenges and complexities of cocreating knowledge with sex workers, we hope to have raised some transferrable messages for researchers working in other criminological topics where deviance, stigma, illegality and crime are a taint on their participants, making methodologies of inclusion difficult. We have raised these difficulties not to deter academics from using PAR or attempting to bring about social change but rather to encourage reflection and discussion. These things are essential if the criminological agenda is serious about fostering meaningful, relevant, and ethical research.

\section{References:}


DISRUPTING THE BOUNDARIES OF THE ACADEME: CO-CREATING KNOWLEDGE AND SEX WORK ACADEMIC-ACTIVISM

Abel, G. 2014. A decade of decriminalisation: Sex work 'down under' but not underground, Criminology and Criminal Justice, 14(5): 580-592.

Agustín, L. 2007. Sex at the Margins: Migration, Labour Markets and the Rescue Industry, London, Zed.

All Party Parliamentary Group for Prostitution .2018. Behind closed doors: Organised sexual exploitation in England and Wales, London, APPG.

Barry, K. 1995. The Prostitution of Sexuality, New York, New York University Press.

Boff, A. 2012. Silence on violence: Improving the safety of women-The policing of off-street sex work and sex trafficking in London. London, London Assembly

Bowen, R., \& Bungay, V. 2015. Taint: An examination of the lived experiences of stigma and its lingering effects for eight sex industry experts, Culture, Health and Sexuality, 18(2): 184-197.

Bowen, R. \& O'Doherty, T. 2014. Participant-driven action research (PDAR) with sex workers in vancouver, BC. In Negotiating Sex Work: Unintended Consequences of Policy and Activism, Ed. S. Majic and C. Showden, pp 53-74, Minnesota, University of Minnesota Press.

Brents, B., \& Sanders, T. 2010. Mainstreaming the sex industry: Economic inclusion and social ambivalence, Journal of Law and Society, 37, 40-60.

Brents, B., Sanders,T \& Wakefield, C (2020) Buying Sex in the Digital Age, London Palgrave Brooks-Gordon, B. 2010. Bellwether citizens: The regulation of male clients of sex workers, Journal of Law and Society, 37(1): 145-170.

Brown, K and Sanders, T. 2017. Pragmatic, progressive, problematic: Addressing vulnerability through a local street sex work partnership initiative special issue of Social Policy and Society 16 (3): 429-441

Campbell, R. \& Stoops, S. 2010. Taking sex workers seriously: Treating violence as hate crime in Liverpool, Research for Sex Work, 12, 9-12.

Canadian Alliance for Sex Work Law Reform. 2014. Canada v. Bedford: The importance of the SCC decision. Available at: http://sexworklawreform.com/wpcontent/uploads/2017/05/canada_vs_bedford_140322.pdf (accessed: 03.04.19)

Clark, J., Dyson, A., Meagher, N., Robson, E. and Wootten, M. 2001 Young People as Researchers: Possibilities, Problems and Politics, Leicester: Youth Work Press.

Colosi, R. 2012. Dirty Dancing? An Ethnography of Lap-Dancing, Routledge: London.

Connelly, L. 2018. Caring for and controlling the subaltern body: Anti-trafficking politics, policy and practice in England and Wales, paper presented at the British Society of Criminology conference, 3-6 July, 2018. Birmingham City University, Birmingham.

Connelly, L., Jarvis-King, L., \& Ahearne, G. 2015. Editorial - Blurred lines: The Contested nature of sex work in a changing social landscape, Graduate Journal of Social Science, 11(2): 4-20. 
DISRUPTING THE BOUNDARIES OF THE ACADEME: CO-CREATING KNOWLEDGE AND SEX WORK ACADEMIC-ACTIVISM

Connelly, L., Kamerade, D., \& Sanders, T. 2018. Violent and non-violent crimes against sex workers: The influence of the sex market on reporting practices in the UK, Journal of Interpersonal Violence, Online First.

Cunningham, S. \& Kendall, TD. 2011. Prostitution, technology, and the law: New data and directions. In Research Handbook on the Economics of Family Law, Ed. LR. Cohen and JD. Wright, p. 221-270, Cheltenham, Edward Elgar Publishing.

Durbar Mahila Samanwaya Committee. 2017. Welcome to Durbar. Available at: https://durbar.org/ (accessed: 03.04.19)

Egan, D. 2003. 'I'll be your fantasy girl, if you'll be my money man: mapping desire, fantasy and power in two exotic dance clubs', Journal for the Psychoanalysis of Culture and Society, 8(1), 277-96.

English Collective of Prostitutes. 2016. Facts about sex work. Available at:

http://prostitutescollective.net/2016/11/facts-sex-work/ (accessed: 03.04.19)

English Collective of Prostitutes. 2016. Decriminalisation of prostitution: The evidence, London, ECP.

English Collective of Prostitutes. 2019. Sex workers are getting screwed by Brexit. Available at: http://prostitutescollective.net/wp-content/uploads/2019/04/Brexit-is-screwing-sex-workers.pdf (accessed: 03.04.19)

Frank, K. 1998 'The production of identity and the negotiation of intimacy in a "gentleman's Club"', Sexualities, 1(2), 175-201.

Garça, M., Gonçalves, M., \& Martins, A. 2018. Action research with street-based sex workers and an outreach team: A co-authored case study, Action Research, 16(3): 251-279.

Gilbert, N. 1997. Advocacy research and social policy, Crime and Justice, 22: 101-148.

Goffman, E. 1963. Stigma: Notes on the Management of Spoiled Identity, Englewood Cliffs, PrenticeHall.

Hardy, K. and Cruz, K. (2018) Affective organizing: Collectivizing informal sex workers in an intimate union, American Behavioral Scientist, 63(2): 244-261.

Hassan, R., Sanders, T., and Mwangi, P. (2018) Sex workers in Nairobi: Services users at BHESP https://journals.le.ac.uk/ojs1/index.php/lias/article/view/2967

Houh, E. \& Kalsem, K. 2015. Theorizing legal participatory action research: Critical race/feminism and participatory action research, Qualitative Inquiry, 21(3): 262-276.

Jahnsen, S. \& Wagenaar, H. 2017. Assessing Prostitution Policies in Europe, London, Routledge.

Jarvis-King, L. (forthcoming) Time is Money: The Commodification of the Indoor Sex Industry, Unpublished PhD Thesis, University of Leeds.

Jeffreys, S. 2009. The Industrial Vagina: The Political Economy of the Global Sex Trade, London, Routledge. 
DISRUPTING THE BOUNDARIES OF THE ACADEME: CO-CREATING KNOWLEDGE AND SEX WORK ACADEMIC-ACTIVISM

Jones, A 2019 Selling Sex Online: Work, Community, and Pleasure in the Erotic Webcam Industry New York University Press

Kempadoo, K. 2004. Sexing the Caribbean: Gender, Race and Sexual Labour, London, Routledge.

Kingston, S. and Thomas, T. (2018) No model in practice: a 'Nordic model' to respond to prostitution? Crime, Law and Social Change, 71(4),423-439

Kinnell, H. 2008. Violence and Sex Work in Britain, London, Routledge.

Klambauer, E. 2018. Policing roulette: Sex workers' perception of encounters with police officers in the indoor and outdoor sector in England. Criminology \& Criminal Justice, 18(3), 255-272.

Letherby, G. 2003. Feminist Research in Theory and Practice, Buckingham: Open University Press.

Levy, J. \& Jakobsson, P. 2014. Sweden's abolitionist discourse and law: Effects on the dynamics of Swedish sex work and on the lives of Sweden's sex workers, Criminology and Criminal Justice, 14(5): 593-607.

Lewin, K. 1946. Action research and minority problems. In. Resolving Social Conflicts, Ed. GW Lewin, New York: Harper and Row.

Mac, J. and Smith, M. 2018. Revolting Prostitutes: The Fight for Sex Workers' Rights, London, Verso.

Macioti P.G., Garofalo Geymonat, G. (Eds.). (2016). Sex workers speak. Who listens? Available at https://opendemocracy.net/beyondslavery. Accessed 1 June 2016.

Mai, N. 2013. Embodies cosmopolitanisms: The subjective mobility of migrants working in the global sex industry, Gender, Place and Culture, 20(1): 107-124.

Metzenrath, S. 1998. In touch with the needs of sex workers. Research for Sex Work (R4SW 1): Peer Education, 1, 11.

Mgbako, C. 2016. To Live Freely in this World: Sex Worker Activism in Africa, New York, New York University Press.

National Ugly Mugs. 2018. National Ugly Mugs statement on the All-Party Parliamentary Group on Prostitution and the Global Sex Trade's report 'Behind Closed Doors - Organised Sexual Exploitation in England and Wales. Available at: https://uknswp.org/um/uploads/National-Ugly-Mugs-statementon-the-All-Party-Parliamentary-Group-on-Prostitution-and-the-Global-Sex-Trades-report-BehindClosed-Doors-Organised-Sexual-Exploitatio.pdf (accessed: 03.04.19)

Phetersen, G. 1989. A Vindication of the Rights of Whores. Seattle, Wash: Seal Press

Pitcher, J. 2015. Direct sex work in Great Britain: Reflecting diversity, Graduate Journal of Social Science, 11(2): 76-100.

Piven, F. 2010. Reflections on scholarship and activism, Antipode, 42(2): 806-810. 
DISRUPTING THE BOUNDARIES OF THE ACADEME: CO-CREATING KNOWLEDGE AND SEX WORK ACADEMIC-ACTIVISM

Oliveria, A. 2019. An action research project with sex worker peer educators in Lisbon, Portugal. In: Dewey, S., Crowhurt, I., Izugbara, C. (eds.) Routledge International Handbook of Sex Industry Research. Abingdon: Routledge.

O’Neill, M. 2001 Prostitution and Feminism, Cambridge: Polity.

O’Neill, M. 2007 'Feminist knowledge and socio-cultural research: ethno-mimesis, feminist praxis and the visual turn', in T. Edwards (ed.), Cultural Theory, London: Sage.

O'Neill, M. 2010. Cultural criminology and sex work: Resisting regulation through radical democracy and participatory action research (PAR), Journal of Law and Society, 37(1): 210-32.

O'Neill, M., Campbell, R., Hubbard, P., Pitcher, J., \& Scoular, J. (2008) Living with the Other: Street sex work, contingent communities and degrees of tolerance, Crime, Media, Culture: An International Journal, 4(1): 73-93.

Rivers Moore, M. 2016. Gringo Gulch: Sex, Tourism, and Social Mobility in Costa Rica. Chicago. University of Chicago Press.

Sanchez Taylor, J. 2006 Female sex tourism: A contradiction in terms? Feminist Review, 83(1): 42-59.

Sanders, T. 2008, Paying for Pleasure, London, Routledge.

Sanders, T. 2009. Controlling the 'anti-sexual' city: Sexual citizenship and the discipling of female street sex workers, Criminology and Criminal Justice, 9(4): 507-525.

Sanders, T. 2018. Enhancing the study of sex work. Sexualities, 21(8): 1346-1350.

https://doi.org/10.1177/1363460718771346

Sanders, T., Connelly, L., \& Jarvis-King, L. 2016. On our own terms: The working conditions of internet-based sex workers in the UK, Sociological Research Online, 21(4): 1-14.

Sanders, T., Cunningham, S., Platt, L., Grenfell, P., \& Macioti, P.G. 2017. Briefing paper: Reviewing the occupational risks of sex workers in comparison to other 'risky' professions. Available at: https://www2.le.ac.uk/departments/criminology/people/teela-sanders/sex-work-and-homicide (accessed: 03.04.19)

Sanders, T., Scoular, J., Campbell, R., Pitcher, J. \& Cunningham, S. 2018. Internet Sex Work: Beyond the Gaze, London, Palgrave.

SCOT-PEP 2014. Press release: New police policy on indoor sex workers revealed: home visits condemned as "raids in disguise", 16 July 2014. Available at: http://www.scotpep.org.uk/news/press-release-new-police-policy-indoor-sex-workers-revealed-home-visitscondemned-raids-disguis (accessed: 03.04.19)

SWARM. 2017. Sex Worker Advocacy and Resistance Movement: What we stand for. Available at: https://www.swarmcollective.org/what-we-stand-for (accessed: 03.04.19) 
DISRUPTING THE BOUNDARIES OF THE ACADEME: CO-CREATING KNOWLEDGE AND SEX WORK ACADEMIC-ACTIVISM

SWARM. 2018. SWARM statement on the APPG on Prostitution's launch of an enquiry into 'pop up brothels', 23 October 2017 Available at:

https://www.swarmcollective.org/blog/?offset=1518171072271 (accessed: 03.04.19)

Ward.,E \& Wylie.,G (Eds.), (2017)Feminism, prostitution and the state: The politics of neoabolitionism London and New York: Routledge.

Wahab, S. 2003. Creating knowledge collaboratively with female sex workers: Insights from a qualitative, feminist, and participatory study, Qualitative Inquiry, 9(4): 625-642.

Weitzer R. 2010. The mythology of prostitution: Advocacy research and public policy, Sexuality Research and Social Policy 7(1): 15-29.

\footnotetext{
' Examples of grassroots organising in the UK include but are not limited to: the English Collective of Prostitutes; the Sex Worker Advocacy and Resistance Movement (SWARM); SCOT-PEP; National Ugly Mugs; Ugly Mugs.ie; and the International Union of Sex Workers.

ii Beyond the gaze was funded by the Economic and Social Research Council (ES/M007324/2)

iii Beyond the Gaze produced a film: Online Sex Work in the $21^{\text {st }}$ Century: https://www.youtube.com/watch?v=th-J14CMWQ0\&feature=youtu.be
} 